$\xi=-1$

\title{
Out-of-Plane Behavior of Masonry Wall Strengthened Using Expanded Wire Mesh
}

\author{
S. Kanchidurai ${ }^{\text {* }}$, P. A. Krishanan ${ }^{2}$, K. Baskar ${ }^{3}$, K. Saravana Raja Mohan ${ }^{4}$ \\ ${ }^{1,4}$ School of Civil Engineering, SASTRA Deemed University, Thanjavur, Tamil Nadu, India. \\ ${ }^{2,3}$ Department of Civil Engineering, National Institute of Technology, Trichy, Tamilnadu, India. \\ *Corresponding author: kanchidurai@ civil.sastra.edu ${ }^{I}$
}

\begin{abstract}
Brick masonry is the principal part of the construction industry. This paper presents the result of the expanded wire mesh embedded into the masonry wall panel; expanded mesh (EM) is the inexpensive locally available material on the market. Through the experimental study, the primary affecting parameters recognized, and the methodology of the embedment details established, the preliminary survey was conducted as per the guidelines are given in the ASTM E518. Totally three numbers of control specimen and three numbers of EM embedded specimen are cast, and compressive strength test of masonry prism also evaluated to identify the crack propagation path. The test results turned out to be highly promising, out of plane damage was less in the EM embedded specimen also it was designated the cracks are reduced.
\end{abstract}

\section{Introduction}

In most of the buildings still used load-bearing masonry structures, during the earthquake out-of-plane loading severely affect the masonry part of the building. This paper presents the out-of-plane loading on masonry panel having 470x470x140 mm size with and without EM embedment. The EM is embedded on the surface of the brick for two courses first then it bends in the bed joint after again erected vertically on the brick surface as shown in figure 1 . The previous research developed in the masonry structures are related to the embedment, which is wrapped in in-built in the plastering. shermi et al. have studied the study on the out-of-plane behavior of URM strengthened with welded wire mesh, the welded wire meshes are embedded by 2,2.5, and $3 \mathrm{~mm}$ diameter steel mesh in this research ductility and out-of-plane flexural capacity significantly increased[1]. Kabir et al. investigated on GFRP retrofitted masonry panel for out-ofplane loading condition, four different type patterns of GFRP strips with different widths were used, this research, using the GFRP strips the masonry panels can significantly increase the ductility of force-displacement reaction, energy incorporation [2], shear behavior [3], resistance to total energy[4]. Mattia Colombo et al. have studied the masonry mortar rehabilitate by using fibre reinforced mortar by spray technology; results show the higher load carrying capacity and significant improvement in the deflection [5]. The application of Carbon fibre reinforced polymer (CFRP) strips applied on the critical surfaces of masonry building showing significant improvement in strength and performance [6]. Najif Ismail and Jason M. Ingham investigated on polymer textile reinforced mortar in masonry panel. In-plane and out-of-plane testing conducted on the strengthened specimen the results show up to $786 \%$ masonry strength was increased in in-plane testing, and there was a notable increment in out-of-plane testing [7]. Embedding twisted stainless steel bar in the existing masonry structure like retrofitting gives higher resistance by the bar during out-of-plane testing, the twisted bar is inserted through drilling operations [8]. Masonry strengthening with CFRP in out-of-plane loading test significant improvement was noted, uniaxial and biaxial CFRP strips applied on the surface of the calcareous masonry panel and achieved significant flexural strength improvement[9], out-of-plane behavior of masonry unit checked by applying $50,100,150 \mathrm{~mm}$ CFRP strips diagonally [10], in hollow block masonry 200mm CFRP strips applied closed longitudinal and transverse manner [11], near surface, mounted CFRP strips (NSM-CFRP) vertically mounted on masonry wall gives significant strength improvement [12]. Engineered Cementitious Composite (ECC) overlay on existing masonry structures are reliable in the strength improvement, $30 \mathrm{~mm}$ overlay of ECC can give $336 \%$ of flexural strength improvement [13]. Masonry surface application of composites like GFRP wires, CFRP strips, and fibre reinforced mortar can considerably improve the flexural strength [14].

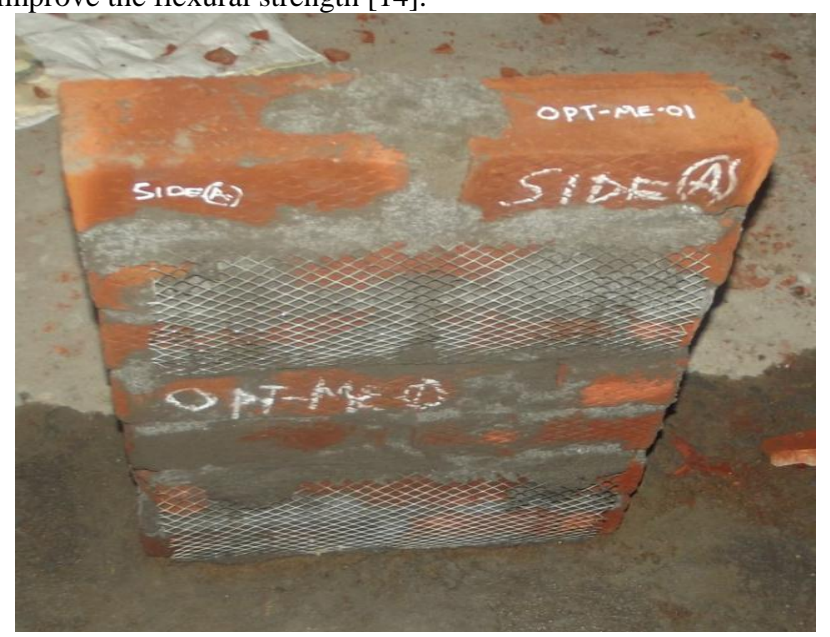

(a) 


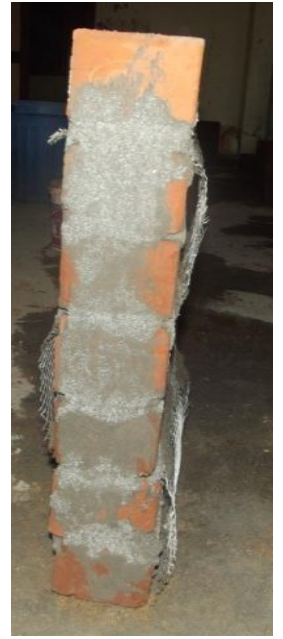

(b)

Fig. 1: EM embedded on the masonry panel for out-of-plane testing (a) elevation of masonry panel, (b) section of the masonry panel

\section{Test Program and Technique}

An innovative masonry panel of expanded wire mesh embedment was developed. To evaluate the masonry strength of embedded panels, the strength of chamber brick, the compressive strength of masonry prism and out-of-plane flexural test of masonry panels were carried out. To evaluate the material quality small-scale tests were conducted on cement, sand, bricks and expanded wires.

\section{Materials}

To make the Mesh embedded masonry panel cement mortar, bricks and expanded mesh were used to be locally available materials, and the galvanized expanded meshes are a costeffective material having Rs.7 per square foot. According to ASTM C150 [15] type I Ordinary Portland Cement 53 grade was used as cement mortar provided by the local supplier. River sand used as Fine aggregate and the specific gravity of the sand was found $2.46 \mathrm{~g} / \mathrm{cc}$ as per the procedure from ASTM C128[16]. Chamber burnt clay bricks are used to construct a masonry panel which is having average dimension $22.5 \times 10.5 \times 8.2 \mathrm{~cm}$. The average compressive strength of clay brick was $12.01 \mathrm{MPa}$ calculated as per guidelines are given by IS3495 [17], the water absorption of the brick $11.296 \%$ comparing its dry weight. The Galvanized iron Expanded wire mesh having the diamond face of $0.71 \mathrm{~mm}$ and the spacing of mesh $9.38 \times 9.38$ measured. The average yield strength of the EM wire is $445.75 \mathrm{MPa}$.

\section{Compressive Strength of Masonry Prism}

The construction of masonry prism as shown in figure 2 with units lay in stack bond in stretcher position. Two number of brick and $10 \mathrm{~mm}$ bed joint was used to make a masonry prism of $224 \mathrm{x} 110 \mathrm{x}$ $170 \mathrm{~mm}$, EM was embedded in mortar bed joints of 1:3 (cement: sand) ratio. The entire compression test was carried out as per guidelines are given in the ASTM C1314 [18]. The compressive strength of each masonry prism strength calculated maximum compressive load applied divided by the net cross-sectional area of the prism, and compressive strength expressed in kilo Newton per millimeter square. Height to thickness ratio considered as the correction factor of the masonry prism, hence the final compressive strength of masonry prism multiplied by the correction factor as given by standard. Totally ten numbers of masonry prism constructed to compare the conventional masonry prism and EM embedded masonry prism. The masonry prism average height to thickness ratio $\left(h_{p} / t_{p}\right)$ was 1.545 and the correction factor considered 0.862 from the ASTM C1314.

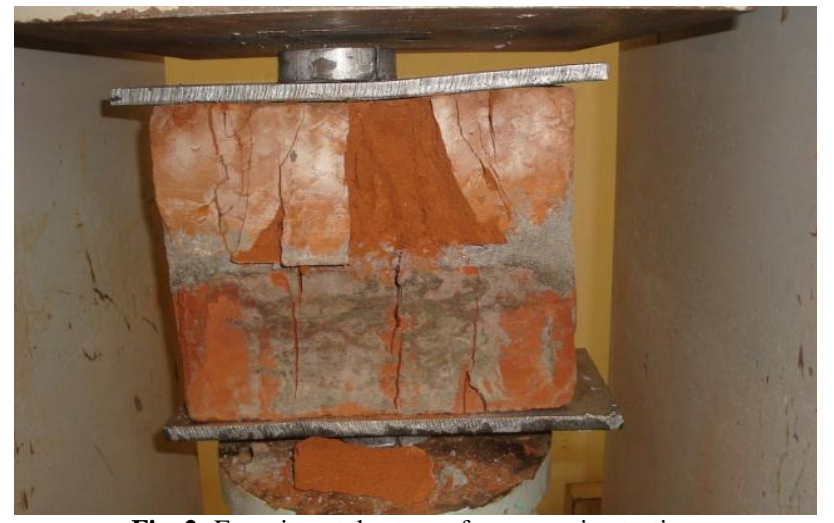

Fig. 2: Experimental set-up of compressive testing

\section{Flexural Strength (out-of-Plane) of Masonry Panel}

The masonry panel fabricated with six-bed joints and one or two perpends alternatively, average dimension of masonry panel was $460 \times 632 \times 146 \mathrm{~mm}$, totally six numbers of specimen fabricated in that three specimens are no mesh embedded units and three specimens are EM embedded (OPT-NE01-03 and OPT-NE01-03). The masonry mortar proportion 1:3 was maintained for six specimens, single layer of EM placed as shown in figure 1. So far the researchers were embedded only at the surface of the masonry, in this paper, the embedded mesh passed both surfaces of specimen and crossing bed joints. Three-point loading method and test method A was performed as per the guidelines are given in the ASTM E518 [16]. The entire test was carried out with 100 tone capacity Universal testing machine of controlled loading application; the speed of testing was maintained with uniform loading speed of $10 \mathrm{kN}$ per minute. All masonry panel curing was done for 28 days at the room temperature $\left(24 \pm 8^{\circ} \mathrm{C}\right)$. Figure 3 shows the experimental set-up of out-of-plane testing
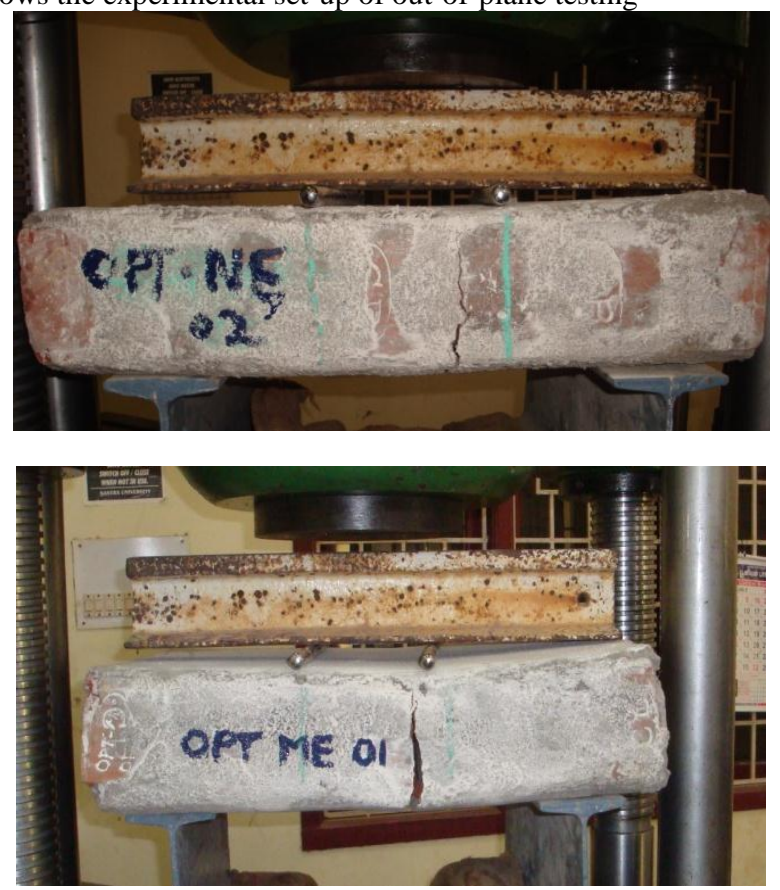

Fig. 3: Experimental set-up of EM masonry panel out-of-plane loading

\section{Construction Technique}

Masonry solid wall panel constructed for $146 \mathrm{~mm}$ including $13.1 \mathrm{~mm}$ plastering cover. The stretcher bond type single brick masonry panel was made with the influence of mesh embedment. The Expanded mesh was bonded for every two stretcher course in between the bed joints and erected vertically like zig-zag manner, Masonry mortar 1:3 (cement: sand) used in the masonry panel. In 
practice this type of mesh bonding construction can be extended for a critical portion of the masonry wall, many previous research works was noticed only sticking GFRP mesh or another wrap on the masonry, but in this, the EM was taken differently.

\section{Results and Discussion}

\section{Compressive Strength of Masonry Prism}

Five specimens were tested for both mesh embedment and no mesh embedment (CSME 01-05 and CSNE 01-05). Application of compressive force gradually increased until the masonry prism sustains maximum, the maximum compressive force and the failure pattern noted to compare the incremental strength of EM embedded masonry. Table 1 shows the maximum sustained compressive load with and without EM embedment. Figure 4 shows the results of compressive strength of masonry prism. The
EM embedded masonry prism resist lager force than the conventional prism without embedment; almost $65 \%$ of average strength increment was noticed from the experimental results. The crack propagation was considerably varying with the applied load because of EM embedment in the prism, the applied compressive force scattered and the crack propagated towards the edges of the masonry prism whereas the conventional masonry prism shows the face shell separation.

\section{Flexural Strength (out-of-Plane) of Masonry Prism}

Four point flexural tests (out-of-plane) carried out according to ASTM E518-15; to evaluate the out-of-plane behavior of the masonry panel six tests were conducted. The maximum resistance offered by the specimen and the development of cracks was noticed, table 2 shows the results of flexural bending (out-ofplane) test.

Table 1: Compressive strength of masonry prism

\begin{tabular}{|c|c|c|c|c|}
\hline \multirow{2}{*}{ specimen } & \multirow{2}{*}{ hp/tp ratio } & \multirow{2}{*}{ Correction factor } & \multicolumn{2}{|c|}{ The compressive strength of prism $\mathrm{f}_{\mathrm{mt}}$ 'MPa.' } \\
\hline & & & CS-NE & CS-ME \\
\hline 01 & 1.545 & 0.862 & 14.65 & 21.11 \\
\hline 02 & 1.545 & 0.862 & 16.77 & 19.96 \\
\hline 03 & 1.545 & 0.862 & 10.08 & 23.35 \\
\hline 04 & 1.545 & 0.862 & 12.34 & 22.01 \\
\hline 05 & 1.545 & 0.862 & 11.92 & 22.60 \\
\hline & & Average & 13.152 & 21.806 \\
\hline
\end{tabular}

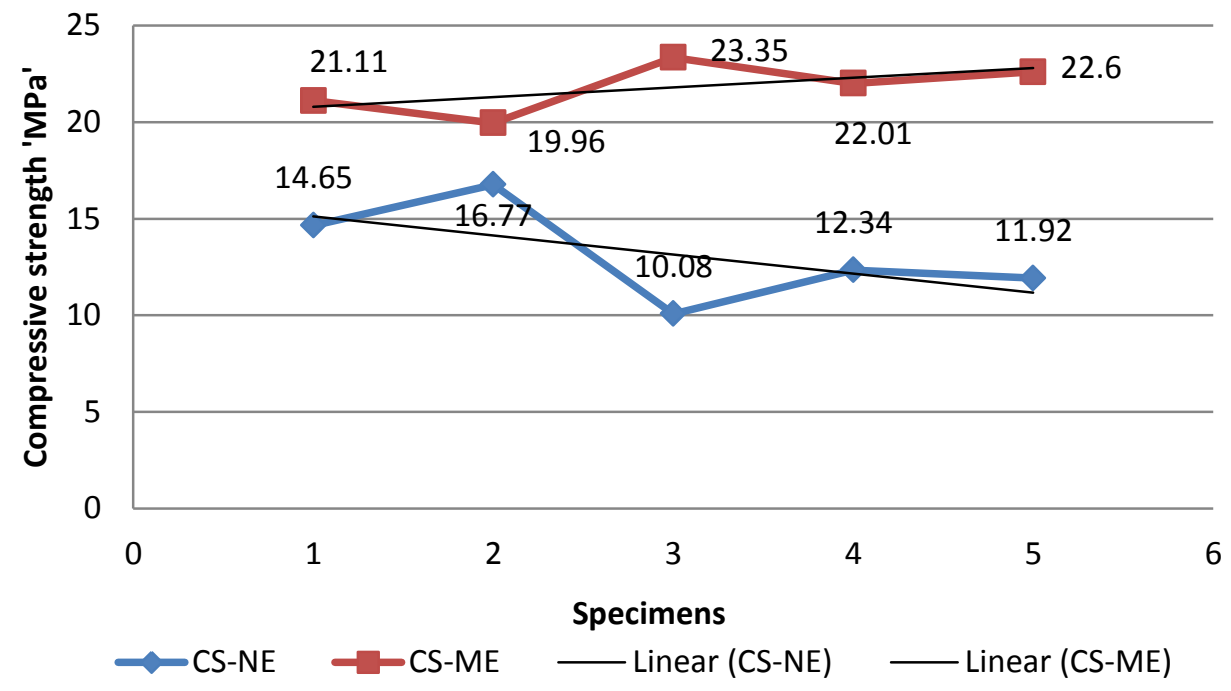

Fig. 4: comparison of embedded mesh and no embedment masonry prism

Table 2: Flexural strength (Out-of plane) of masonry panel

\begin{tabular}{|c|c|c|c|c|c|c|c|}
\hline Specimen & Type & $\begin{array}{c}\text { Maximum Load } \\
\text { 'kN.' }\end{array}$ & Average & $\begin{array}{c}\% \text { of } \\
\text { increase }\end{array}$ & Weight Ps 'kN.' & span & 'R' 'Pa' \\
\hline OPT-NE 01 & Control & 8.10 & \multirow[t]{3}{*}{7.667} & \multirow[t]{3}{*}{-} & 0.54 & \multirow[t]{6}{*}{$0.513 \mathrm{~m}$} & 0.617 \\
\hline OPT-NE 02 & Control & 7.50 & & & 0.622 & & 0.574 \\
\hline OPT-NE 03 & Control & 7.40 & & & 0.59 & & 0.566 \\
\hline OPT-ME 01 & Embedded & 12.30 & \multirow[t]{3}{*}{11.37} & \multirow[t]{3}{*}{48.24} & 0.613 & & 0.931 \\
\hline OPT-ME 02 & Embedded & 9.65 & & & 0.604 & & 0.734 \\
\hline OPT-ME 03 & Embedded & 12.15 & & & 0.637 & & 0.920 \\
\hline
\end{tabular}




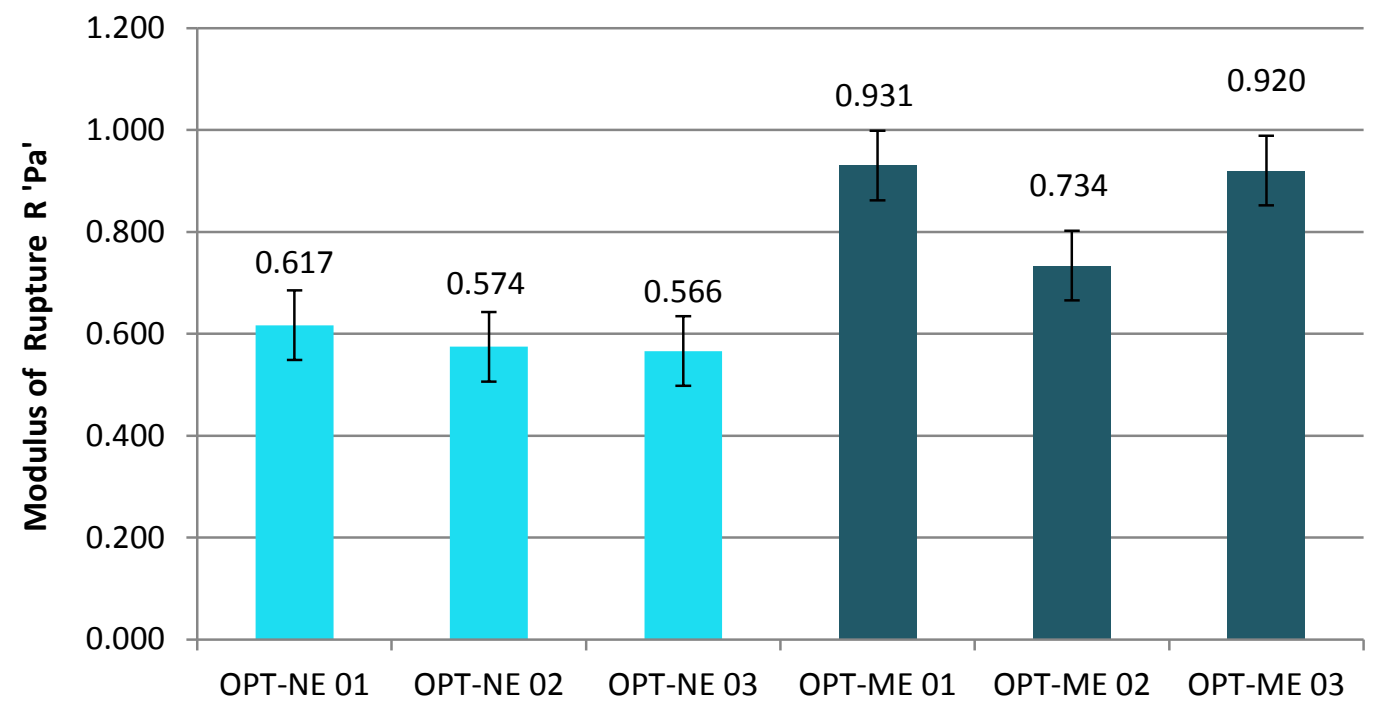

Fig. 5: Flexural strength of embedded and nonembedded masonry panels

\section{Conclusion}

The performance of the EM embedment is preventing the crack opening and after collapsing there is no complete separation noticed in the masonry panel.

1. The compressive strength of masonry prism was increased compared to no expanded mesh embedded panel (control masonry panel).

2. Failure cracks are propagated towards edge of the masonry prism at the time of compressive test and because of this specimen identified the splitting was reduced in the masonry

3. The experimental results reported here that the Modulus of rupture of masonry prism produced higher with embedment of expanded mesh

\section{Acknowledgement}

The authors would like to thank the Vice-Chancellor of SASTRA DEEMED TO BE UNIVERSITY for having provided experimental facilities in the Civil Engineering Department to do this research work, and also the continual support and encouragement given during this research work.

\section{References}

[1] Shermi C, R.N. Dubey, Study on the out-of-plane behaviour of unreinforced masonry strengthened with welded wire mesh and mortar, Construction and Building Materials 143 (2017) 104-120.

[2] Razieh Sistani Nezhad, Mohammad Z. Kabir, Experimental investigation on out-of-plane behavior of GFRP retrofitted masonry panels, Construction and Building Materials 131 (2017) 630-640

[3] R. Capozucca, V Ricci. Bond of GFRP strips on modern and historic brickwork masonry. Composite Structures 140 (2016) 540-555

[4] S.Saileysh Sivaraja, T.S.Thandavamoorthy, S.Vijayakumar, S.Mosesaranganathan, P.T.Rathnasheela, and A.K.Dasarathy. GFRP Strengthening and Applications of Unreinforced Masonry wall (UMW). Procedia Engineering 54 (2013) 428-439

[5] Mattia Colombo, Tiago Valente, Joaquim A.O. Barros, Alessandra Aprile, Lúcio Lourenço. Fibre reinforced mortar application for the out-of-plane strengthening of schist walls. Construction and Building Materials 121 (2016) 185-197

[6] Alessia Monaco, Giovanni Minafo, Calogero Cucchiara, Jennifer D'Anna, Lidia La Mendola. Finite element analysis of the out-ofplane behavior of FRP strengthened masonry panels. Composites Part B 115 (2017) 188-202
[7] Najif Ismail, Jason M. Ingham. In-plane and out-of-plane testing of unreinforced masonry walls strengthened using polymer textile reinforced mortar. Engineering Structures 118 (2016) 167-177

[8] Najif Ismail, Jason M. Ingham. In-situ and laboratory-based outof-plane testing of unreinforced clay brick masonry walls strengthened using near surface mounted twisted steel bars. Construction and Building Materials 36 (2012) 119-128

[9] Laura Anania, Giuseppe D'Agata, Cristian Giaquinta, Antonio Badala. Out of Plane Behavior of Calcareous Masonry Panels Strengthened by CFRP. APCBEE Procedia 9(2014)401-406

[10] Ozgur Anil, Muhammed Tatayoglu, Murat Demirhan. The out-ofplane behavior of unreinforced masonry brick walls strengthened with CFRP strips. Construction and Building Materials 35 (2012) 614-624

[11] TanTrung Bui, Ali Limam. The out-of-plane behavior of hollow concrete block masonry walls unstrengthened and strengthened with CFRP composite. Composites: Part B 67 (2014) 527-542

[12] Dmytro Dizhur, Michael Griffith, Jason Ingham. Out-of-plane strengthening of unreinforced masonry walls using near surface mounted fibre reinforced polymer strips. Engineering Structures 59 (2014) 330-343

[13] Y. Lin, Derek Lawley, Liam Wotherspoon, JasonM. Ingham. Outof-plane Testing of Unreinforced masonry walls Strengthened Using ECC Shotcrete. Structures 7(2016)33-42

[14] Natalino Gattesco, Ingrid Boem. Out-of-plane behavior of reinforced masonry walls: Experimental and numerical study. Composites Part B 128 (2017) 39-52

[15] American Society for Testing and Materials (ASTM), Standard Specification for Portland Cement1, ASTM C150/C150 M - 17

[16] American Society for Testing and Materials (ASTM), Standard Test Method for Relative Density (Specific Gravity) and Absorption of Fine Aggregate, ASTM C128-15

[17] Bureau of Indian standard (BIS), Methods of tests of burnt clay building bricks, IS 3495: 1992 parts 1-4

[18] American Society for Testing and Materials (ASTM), Standard Test Method for Compressive Strength of Masonry Prisms, ASTM C1314 - 16

[19] American Society for Testing and Materials (ASTM), Standard Test Methods for Flexural Bond Strength of Masonry, ASTM E518 / E518-15 